\title{
Un modelo conceptual para analizar los debates electorales en TV. Mediatización y ceremonias televisivas
}

\author{
A conceptual model for the analysis of electoral debates on TV. \\ Mediatization and television ceremonies
}

Carles Marín Lladó. Universidad Rey Juan Carlos. España. carles.marin@urjc.es

$[\underline{\mathrm{CV}}]$ (1) $\mathrm{G}$

José Manuel Pérez Tornero. Universidad Autónoma de Barcelona. España.

josepmanuel.perez@uab.es

$[\underline{\mathrm{CV}}]$ (1)

Cómo citar este artículo / Referencia normalizada

Marín Lladó, C. y Pérez Tornero, J. M. (2020). Un modelo conceptual para analizar los debates electorales en TV. Mediatización y ceremonias televisivas. Revista Latina de Comunicación Social, (76), 229-245. https://www.doi.org/10.4185/RLCS-2020-1445

\section{RESUMEN}

Introducción: Los debates electorales de televisión estaban concebidos para proporcionar a los espectadores información contrastada sobre programas políticos y candidatos, pero en los últimos tiempos el escenario político y el de los medios de comunicación han cambiado tanto que estos programas han pasado a convertirse en puros acontecimientos mediáticos. En este artículo se analiza cómo el discurso y la posición actancial de los candidatos de los debates electorales presidenciales de televisión se acomodan en función del show mediático para consagrarlos como ganadores $\mathrm{y}$, en el mejor de los casos, como héroes televisivos; o también todo lo contrario. Metodología: Nuestro principal objetivo no es de carácter empírico sino teórico y metodológico. No queremos describir el funcionamiento de los debates electorales en España. Tratamos de poner en pie y de probar un modelo de análisis aplicable a diversos contextos y, de esta manera, contribuir a fijar una serie de conceptos operativos en un nuevo marco conceptual. Resultados: La aplicación del modelo propuesto permite, entre otras cosas, identificar tanto los efectos de la mediatización política como la marcada tendencia a crear Gestalt ceremoniales ante acontecimientos mediáticos planificados. Asimismo, en el marco de esa Gestalt, permite reconocer el valor de la gradación de la agresividad y la conflictividad por parte de los diferentes candidatos presidenciales en el debate televisado. Conclusiones: En función del punto de vista utilizado, observamos una clara correlación entre la citada gradación de la agresividad y el índice de polarización que se ha experimentado en la opinión pública en las últimas décadas, así como en la tendencia a la espectacularización conflictiva que se ha vivido en los géneros televisivos a partir de nueva forma de hacer política y periodismo.

PALABRAS CLAVE: debates; televisión; elecciones generales; España; análisis del discurso. 


\begin{abstract}
Introduction: Political debates on television were usually designed to provide viewers trustful information about the political candidates and their manifestos. Unfortunately, the political situation and the communication media have undergone such a change that those manifestos have become mere mediatic representations. In this article, we will analyze how the speech and the actantial position of the candidates get adjusted according to the mediatic show to become the winners, or in the best scenario, as television heroes, or maybe just the opposite. Method: Our main objective is not empirical but theoretical and methodological. We do not wish to describe the electoral debates in Spain. We are trying to highlight a model of analysis, which can be applied to different contexts, so we can contribute to fix a series of operative concepts, in a new framework. Results: To apply the suggested model will allow, among other things, to identify not only the political mediatization effects but also the marked tendency to create ceremonial gestalt in front of planned mediatic events. At the same, time it will allow to identify the aggressiveness and conflictive graduation of the different presidential candidates on the televised debates. Conclusions: From our point of view, it is a clear correlation with the polarization index that public opinion has experienced as well as a tendency to a conflictual spectacularization that television genres have developed in the last decades as a new way of doing politics and journalism.
\end{abstract}

KEYWORDS: debate; television; presidential election; Spain; discourse analysis.

\title{
CONTENIDOS
}

1. Introducción y marco Teórico. 1.1 La mediatización de la política. 2. Metodología. 2.1 El modelo conceptual. 3. Análisis. 3.1 Acontecimiento mediático. 3.2. Regulación conflictiva. 3.3. Marco general del acontecimiento. 3.4. La secuencia narrativa de la prueba. 3.5. Las acciones de los protagonistas. 3.6. Las estrategias enunciativas. 4. Resultados y conclusiones. 5. Referencias.

\section{Introducción y marco teórico}

Cualquier proceso político de carácter electoral consiste esencialmente en una competición entre partidos, programas y candidatos que tratan de obtener el voto de los electores. De aquí que durante las campañas los debates televisivos entre candidatos se presenten -ante la opinión pública, pero también en el marco de las ciencias políticas y de la comunicación- como foros de deliberación y confrontación, estrechamente ligados a conceptos tales como democracia deliberativa (Dahl, 1991), esfera pública (Habermas, 1983), etc. En este sentido, hay bastante consenso -político y académicoen contemplarlos como un elemento de "salud en el sistema democrático" (Quintas, 2010), de "formación del espíritu crítico" (Proaño, 2002) y de "información política” (Herrero y Benoit, 2009).

Ahora bien, esto es válido solo en teoría. Tanto el escenario político como el mediático han sufrido recientemente cambios tan decisivos que el estatuto de los debates televisivos se ha modificado sustancialmente. De ser elementos que estaban destinados a proporcionar información contrastada sobre programas políticos y candidatos (Soengas, 2009; Galindo, 1998) han pasado a convertirse en puros acontecimientos mediáticos (media events), tal y como en su día los definió Elihu Katz (1980). O sea, eventos construidos a partir de los medios, cuyas principales características son: 1) El ser transmitidos en directo; 2) Responder a una planificación previa; 3) Estar bien localizados en el espacio y el tiempo; 4) Poner énfasis en protagonistas presentados como héroes; 5) Potenciar un alto sentido dramático y ritual. 6) Presentarse como un programa de visionado cuasi obligatorio. De aquí que tengan tendencia a adquirir un marcado carácter espectacular (Padilla, 2014) y que se rijan, generalmente, más por la lógica mediática (Altheide y Snow, 1979) que por la de la política institucionalizada (Chadwick, 2013). Este fenómeno está íntimamente conectado con lo que muchos 
autores han llamado mediatización de la vida (Livingstone, 2009; Hepp, 2011; Hjarvard, 2013), y más concretamente, mediatización de la política (Bennett, 1995; Meyen, Thieroff, y Strenger, 2014), un proceso que está cambiando no solo la comunicación política (Cook, 1988; Blumler y Gurevitch, 1995), sino la política en sí misma (Sunstein, 2002; Allern y Blach Orsten, 2011).

Las consecuencias prácticas de estos cambios no han tardado en dejarse notar. Los debates televisados -en la mayoría de los países donde se practican- tienden a reducirse a una competición entre líderes muy centrada en el aspecto carismático liderazgo que definió Max Weber por oposición a la política consuetudinaria y legal, y, por tanto, bastante relacionados con lo que se ha denominado "populismo mediático" (Postill, 2018; Krämer, 2014). Al mismo tiempo, se integran sistemáticamente en flujos discursivos paralelos -especialmente en redes sociales- que suelen reforzar los aspectos emocionales y agresivos del discurso (Thompson, 2016). Pero estos cambios exigen también modificaciones profundas en el punto de vista de la investigación académica.

\subsection{La mediatización de la política}

La mediatización de la comunicación (Livingstone, 2009; Livingstone y Lunt, 2014) y de la comunicación política en particular es descrita por muchos autores como la intervención reciente de las instituciones mediáticas en las instituciones políticas tradicionales (Bennett y Entman, 2001; Blumler y Gurevitch, 1995). En ocasiones se ha llegado a hablar incluso de colonización de la política por parte de los medios (Berardi, 2017; Hepp, 2011).

La mediatización es un fenómeno observable (Meyen, Thieroff y Strenger, 2014) cuando -sobre todo a partir de los años 90- los medios de comunicación de masas fueron mutando paulatinamente su habitual función de informar sobre la política desde fuera de la política, por otra bien distinta: ser participantes activos desde dentro de la política (Blumler y Gurevitch, 1994; Cook, 1998; Sparrow, 1999). Pero, con los procesos de globalización de la televisión, la digitalización de las comunicaciones, la aparición de internet y la web, y, sobre todo, de la popularización de las redes sociales, el fenómeno no ha hecho más que avanzar y consolidarse (Casero-Ripollés, 2009; Strömbäc, 2008; Strömbäc y Esser, 2014).

Nos encontramos ya, por tanto, en un momento en que la mediatización de la política parece ser un proceso realizado totalmente. La acción política depende decisivamente de los medios de comunicación, y las tradicionales instituciones políticos -partidos, parlamentos, gobiernos, etc.- son ya casi una especie de provincias de los nuevos imperios mediáticos (Berardi, 2017). Podemos encontrar muchos ejemplos de los procesos señalados. Los gobiernos configuran su imagen pública a través de sus portavoces -ruedas de prensa y sus gabinetes de comunicación- más que por sus decisiones y acciones (Canel y Sanders, 2012). Las deliberaciones parlamentarias suelen ser la ocasión para escenificar una suerte de representación mediática espectacular, más que auténticos foros de deliberación, negociación y adopción de decisiones. Los líderes políticos, por su parte, actúan más como estrellas mediáticas que como estrategas y directores de la acción política (Adam y Maier, 2010; Enli y Skogerbo, 2013). Y, por su parte, los ciudadanos parecen ser meros espectadores que asisten -entre entretenidos y desencantados- al espectáculo de la política, más que ser ciudadanos activos que participantes activos en la toma de decisiones en los asuntos públicos (Bennet y Entman, 2001; Bucy y Gregson, 2001).

Podemos establecer, pues, mediante el análisis transversal de los ejemplos señalados, algunas grandes líneas que enmarcan el proceso de mediatización actual de la política y que nos acercan al cambio de enfoque teórico que necesitamos: 
1. Las instituciones mediáticas actúan ya como auténticos agentes y actores políticos. Van mucho más allá del papel informativo, orientador y vigilante del poder que ocupaban con anterioridad (Blumler y Gurevitch, 1995; Casero-Ripollés, 2008). En la actualidad, muchos medios han adquirido, por sí mismas, el estatuto de agente político de primera magnitud: se sienten representantes de la opinión pública, tienen su propio programa de acción política y una estrategia comparable a la de los propios partidos -hasta el punto de que la acción de estos, muchas veces, viene a ser subsidiaria del sistema de medios-.

2. La visibilidad mediática (Heinich, 2012) está convirtiéndose en el principal activo para actuar en política, lo que se está traduciendo en una continua y constante irrupción de estrellas de los medios -actores, periodistas, participantes en programas de telerrealidad, cantantes, intelectuales mediáticos, etc.- en el campo de la política activa. De hecho, muchos medios actúan, consciente y sistemáticamente, como plataformas de lanzamiento y de promoción de políticos, y/o de estrategias políticas. Sus platós -en el caso de las televisiones- tratan de amparar a las estrellas emergentes de la política y, al mismo tiempo, ofrecer un foro permanentemente abierto a los líderes ya consagrados, pero tratando siempre de diseñar su propio "equipo de líderes políticos", tratando de que estos se relacionen indisolublemente con la imagen del medio. Además, muchos de sus programas y producciones no responden a una estrategia de información periodística stricto sensu, sino a una estrategia de auténtica actuación política.

3. Los líderes y los diversos agentes políticos se han reconfigurado en actores mediáticos (Balmas, Sheafer, 2013; Enli y Skogerbo, 2013). Esto se aprecia, en parte, en que, generalmente, pasan más tiempo y dedican más atención a los medios de comunicación que al trabajo estrictamente político. Han dado así, consciente o inconscientemente, un paso decisivo hacia la política carismática, y a la vedetización del liderazgo político, lo que resulta congruente con el fenómeno de mediatización progresiva que se da en la sociedad. Esto explica que su presencia en los medios no suela distinguir ya entre ámbitos políticos y otros tipos de ámbitos (familiar, social, etc.), y que, por tanto, no se reserve a los primeros. Al contrario, cada vez más los políticos frecuentan los espacios de información mundana y social, sin ningún tipo de reserva ni restricción. Del mismo modo, cada vez es más frecuente que los políticos se presten, muy a menudo, a posar ante las cámaras como modelos o como actores de cine y televisión, alejados, pues, de los ámbitos políticos que le son propios. También, cada vez es más frecuente que tiendan a visibilizar el lado privado de su existencia -hogares, amistades, familia, etc.-, lo que ha propiciado, en algunas ocasiones, que algunos candidatos busquen, incluso, en ciertas contiendas electorales "matrimonios por conveniencia" con estrellas del cine, la música o la televisión.

4. Los expertos y los trabajos especializados en la comunicación política -asesores, diseñadores, propagandistas, expertos en encuestas y redes sociales, etc.- han llegado a imponer un nuevo modelo de gestión política dominado por la gestión comunicacional (Dahlgren, 2005), lo que ha llegado a influir decisivamente en la toma de decisiones políticas. Muchas decisiones, antes estrictamente políticas, dependen -en un contexto de mediatización intensiva como el que vivimos- más de los expertos y asesores de comunicación que de los agentes y procedimientos tradicionalmente institucionalizados de los partidos, gobiernos y parlamentos.

5. Los ciudadanos tienden a percibir, cada vez más, la política como espectáculo (show) y como espacio de representación, lo que está generando distanciamiento, abstencionismo electoral y escepticismo ante las posibilidades de la democracia. En este sentido, el desencanto que cunde en la opinión pública tiende a crear el descrédito de las instituciones políticas hasta alcanzar cuotas insospechadas. Y con ello -y paralelamente- se va produciendo un progresivo descrédito de la función que correspondería a los medios, especialmente en lo que se refiere a su función periodística. 
Hasta aquí, las transformaciones que se relacionan con el cambio de la comunicación política. Pero, junto a ellas, se está produciendo un cambio que afecta, también, a la misma conformación de las instituciones políticas y a su funcionamiento, regulación y normatividad.

También este cambio es producto de la mediatización intensiva y afecta a la concepción y a la práctica de la democracia a dos de sus componentes clave: a) a la estructuración de la acción política; y, otra, b) a la modalidad en que la política contribuye a la conformación de la esfera pública general.

Por lo que hace la estructuración de la acción política, lo que está cambiando es la organización del ciclo político canónico del sistema democrático. Un sistema político democrático se entendía como un proceso, en forma de ciclo, estructurado en cuatro fases o momentos, que se encadenan sucesivamente, y que se hallan estrechamente relacionados entre sí (Tavoillot, 2019). Así, se distinguían las siguientes fases:

- Un momento deliberativo que coincide tanto con la deliberación parlamentaria como la deliberación abierta en los foros públicos.

- Un momento de resolución y de toma de decisiones que se corresponde con las elecciones y con las votaciones parlamentarias.

- Un momento de acción y ejecución que se lleva a cabo por los gobiernos y por la administración.

- Un momento de rendimiento de cuentas que es un ejercicio de información, explicación y transparencia.

Pues bien, para cada uno de estos momentos, existían instituciones específicas -partidos, parlamentos, gobiernos, elecciones, representantes, autoridades, etc.- con reglas y protocolos precisos. Sin embargo, la mediatización experimentada en la sociedad en las últimas décadas ha alterado profundamente este modelo de estructuración (Castells, 2009; Beck, 1996).

Los ámbitos en que se ejerce la política, anteriormente reservados a los agentes políticos tradicionales y cerrados al resto, tienden ahora a ser públicos y abiertos. Y muchas veces, lo son en tiempo real. Sucede así, por ejemplo, con las reuniones de partidos, los debates parlamentarios, mítines, ceremonias políticas, etc. La política se hace, cada vez, más participativa, más incluyente de la cuasi totalidad de los ciudadanos/as, más visible y más simultánea (casi se vive en tiempo real).

Pero todo esto, en realidad, se hace a través de los medios, y el hecho tiene consecuencias: la acción política parece requerir cada vez menos presencialidad y empieza a hacerse más virtual; $\mathrm{y}$, como consecuencia de ello, se debilitan o se transforman muchos de los conceptos básicos del sistema político tradicional.

Los conceptos de representatividad y de participación se modifican, puesto que el funcionamiento de las instituciones no exige ya ni la presencia ni la acción física de los agentes. Los conceptos de rendimiento de cuentas o de transparencia también cambian. En la misma medida, se tiende propiciar un estado de visibilidad constante en el ámbito de la acción política y que pierden sentido los actos puntuales de información.

Y, finalmente, cambian también los tiempos y ritmos de la acción política. Todas las acciones tienden -en este contexto- a la simultaneidad y, por tanto, a reducir las duraciones de los procesos, con lo cual quedan pocas posibilidades de acción estratégica en la que el control de los tiempos siempre cuenta. 
El proceso de mediatización ha tendido, pues, a situar la política bajo una especie de panóptico que asegura un estado de visibilidad extrema, ha comprimido todos los tiempos, y como consecuencia de ello, ha alterado las relaciones de poder.

El nuevo panóptico mediático ha instaurado la figura de un observador permanente, un público global, con el don de la omnisciencia que actúa, siempre, como destinatario de la acción política y se ha erigido en el gran sancionador -un actante en posición de destinatario- de todas y cada una de las acciones y gestos de los políticos. Así, por poner un ejemplo, no tiene el mismo sentido un debate parlamentario en el que los distintos grupos se dirigían, tradicionalmente, solo al resto de representantes que un debate que está siendo retransmitido por televisión y que todo el mundo contemplará. En este último caso, el destinatario y el sancionador final coinciden en un solo actor: el público de la televisión.

Por otro lado, la mediatización continua que hemos vivido en las últimas décadas ha comprimido los ciclos políticos. Ha acelerado los procesos y ha generado un fenómeno de implosión temporal. Todo sucede en una especie de punto Aleph -que ya describió Borges en un cuento del mismo nombre-, en el que todos los acontecimientos y objetos del mundo se encuentran simultáneamente. Cualquier acción política, de ahora en adelante, tenderá a configurarse en este nuevo horizonte temporal de implosión.

Y, resultado de todo ello, ha sido una profunda transformación en las relaciones de poder. No hay el mismo margen de libertad de actuación para los agentes que participan en una reunión a puerta cerrada que el que se tiene cuando esa reunión se realiza a la vista de todo el mundo y es registrada y conservada para siempre, por medios electrónicos. La mediación (o mediatización) cuasi universal ha trastocado, pues, el margen de libertad de los políticos y ha introducido una visibilidad general que ha dado lugar una nueva estructura de poder. Actualmente, en todas las relaciones políticas interviene un actor/actante decisivo: la audiencia mediática, es decir, un colectivo de espectadores susceptible de ampliarse constantemente- que se convierte en juez universal, que sanciona y califica las acciones de los políticos. El hecho significativo es que este nuevo actor/actante es fruto de una construcción consciente y sistemática de los mismos medios de comunicación que han dejado ya de ser mediadores y han pasado a ser participantes.

Los fenómenos descritos -especialmente el de la creación del público universal- han sustraído a las instituciones políticas clásicas la centralidad, distancia e, incluso, solemnidad que tenían. La política de hoy parece resolverse de un modo bastante informal y transversal -un poco en todas partes, y en todas partes a la vez-, dispersando los momentos de deliberación, de negociación y de ejercicio del poder. Más que un poder institucional constituido y estable, lo que existe, hoy en día, es una red compleja y dispersa de microespacios de poder. Es justamente en este contexto en el que los debates electorales televisados adquieren un nuevo estatuto, una nueva función y un nuevo significado, que exige un cambio conceptual y teórico importante.

\section{Metodología}

Tomando siempre como objeto de estudio los debates electorales televisados en el nuevo contexto de mediatización intensiva, nos proponemos en este texto los siguientes objetivos:

1. Diseñar las bases de un modelo conceptual que permita describir y analizar con eficacia los debates políticos actuales dentro del marco de, por un lado, a) la mediatización intensiva de la política y, por otro, b) de la tendencia de las televisiones (medios audiovisuales, en general) a construir eventos mediáticos (media events) que, en el contexto de una creciente espectacularización, tienden a adoptar funciones ceremoniales. 
2. Describir con precisión los diversos cursos narrativos y estrategias enunciativas presentes en los debates políticos audiovisuales, en el nuevo marco ceremonial, con especial atención a los que constituyen el núcleo de la competición entre candidatos, lo que llamaremos, siguiendo la propuesta de la semiótica narrativa: la prueba calificante.

3. Ofrecer una primera aproximación de aplicación de dicho modelo a un curso de debates políticos concretos, lo cual nos permitirá iniciar la validación del método conceptual propuesto -a modo de experiencia piloto-. Nos estamos refiriendo a un corpus limitado de debates -seleccionado intencionalmente, en el que se incluyen los principales debates políticos celebrados en la historia democrática de España en las elecciones generales y con participación de los principales candidatos a la Presidencia del Gobierno.

Nuestro principal objetivo, pues, no es de carácter empírico sino teórico y metodológico. No queremos describir el funcionamiento de los debates electorales en España. Tratamos de poner en pie y de aplicar y probar un modelo de análisis -un nuevo marco conceptual- aplicable a diversos contextos que se corresponda con el contexto de mediatización intensiva y de dramatización ceremonial de la vida política que estamos viviendo en la actualidad.

Para cumplir estos objetivos, utilizaremos las aportaciones de las teorías de los marcos (Frame analysis) desarrollada, entre otros, por (Goffman, 1974); posteriormente, por la sicología cognitiva, la semántica y el análisis del discurso político (Lakoff, 2017). También usaremos el punto de vista desarrollado por la antropología y la sociología de la comunicación, especialmente, la teoría de la televisión ceremonial (Dayan y Katz, 1994), así como el análisis de los rituales mediáticos propuesto (Couldry, 2003).

En relación con el estudio de las nuevas narrativas involucradas en los debates televisivos actuales, aplicaremos el análisis semionarrativo (Greimas, A., Courtés, J. et al., 1982), por un lado, y los estudios del análisis funcional aplicado al discurso político (Benoit, 1995). Por lo que hace a las aportaciones del análisis del relato. Esta teoría -desde las funciones narrativas (Greimas, A., Courtés, J. et al.,1982) sobre las funciones de los personajes en los cuentos hasta llegar a la semiótica narrativa teorizada por la Escuela de París y A. Greimas- nos brinda un modelo formal para explicar el papel que cumplen los actantes en toda estructura narrativa. Utilizaremos las definiciones de dichas funciones para analizar el autoposicionamiento que cada candidato muestra en los debates, y cómo este evoluciona a lo largo del mismo.

\subsection{EI modelo conceptual}

Desde nuestro punto de vista, un debate electoral de TV es: 1) un acontecimiento mediático (media evento) (Katz, 1980), con carácter de: 2) ceremonia televisiva, dentro del género de la confrontación (Dayan y Katz, 1994), organizado en un marco político previo a un proceso electoral que se rige por 3) un sistema de regulación variable pero acordado por un heterogéneo conjunto de instancias y agentes -el poder legislativo, el judicial, la tradición previa de debates, los acuerdos entre las fuerzas políticas, los candidatos, los medios de comunicación, el cuerpo profesional de los periodistas, etc.-. Este acontecimiento mediático, se desarrolla en 4) una constelación de eventos mediáticos y no mediáticos -que se subdivide en: a) ámbito mediático central -configurado tecnológica, espacial y temporalmente-, generalmente una cadena o cadenas de televisión-, acompañado de diversos otros; b) ámbitos mediáticos periféricos -que van desde programas previos y posteriores; redes sociales; otros medios masivos, etc.- (Gil de Zúñiga, Jung y Valenzuela, 2012). Todos estos ámbitos mediáticos se complementan con c) acontecimientos no mediáticos -reuniones, actos, mítines, etc.-. 
A las relaciones entre los diferentes ámbitos mediáticos y no mediáticos, le llamaremos 5) arquitectura del acontecimiento mediático. Y a los flujos informacionales que se producen dentro del conjunto de ámbitos, le llamaremos 6) cursos discursivos del acontecimiento. Dentro de los cursos discursivos de un acontecimiento mediático -en este caso, un debate electoral- identificaremos varios cursos narrativos específicos, en función de los diferentes ámbitos de que nos ocupemos -ámbito mediático central o alguno de sus ámbitos periféricos-. También es posible, tomando en cuenta las posibilidades de la convergencia mediática y de la intertextualidad posible, identificar cursos narrativos transmedia, en los que se mezclen diversos ámbitos de la arquitectura del acontecimiento mediático.

Con objeto de identificar un acontecimiento mediático -en este caso, los debates electorales televisados- y para poder analizarlo de manera sistemática, identificaremos los siguientes componentes:

a) El marco general del acontecimiento, que analizaremos en tres dimensiones: 1) pragmática o performativa (Austin, 2016; Searle, 1969), 2) ritual o ceremonial (Dayan y Katz, 1994) y teatral o lúdica (play) (Goffman, 1974).

b) El tipo de relato que se da en diferentes cursos narrativos, sea en el ámbito del debate concreto o en algunos otros ámbitos complementarios. En todos esos casos, nos ocuparemos de: 1) El marco o género en que se inscribe, o sea, la forma que adopta. 2) El análisis actancial y actoral de las diferentes figuras participantes -en este caso, los candidatos y los periodistas- de los actores-candidatos, y su posición actancial y narrativa. 3) El desarrollo semionarrativo.

Tomaremos en cuenta cómo el curso narrativo -especialmente en el debate propiamente dichoconsigue modificar la posición actancial de los candidatos a medida que cada uno de ellos actúa y se relaciona enunciativamente con el resto. Prestaremos especial atención a la secuencia de la prueba, en la que un sujeto demuestra sus competencias y estas le son reconocidas o sancionadas finalmente. En nuestro caso, los candidatos son los actores que tratan de superar la prueba, mientras que la audiencia es el sujeto destinatario que efectúa la sanción. Para ello, ponen en marcha una serie de acciones discursivas que definiremos con los términos empleados por Benoit: a) Aclamaciones, B) Ataques. Y C) Defensas. El conjunto de acciones discursivas de cada uno de los candidatos viene a configurar, para cada uno de ellos, una estrategia discursiva que contribuye a completar el perfil actoral de cada candidato.

\section{Análisis}

\subsection{Acontecimiento mediático}

Los dos debates electorales presidenciales televisados, celebrados con ocasión de las elecciones generales en España el 28 de abril de 2019, pueden ser descritos coherentemente a partir de los términos usados en nuestro modelo conceptual. He aquí los núcleos centrales de sentido identificados y que se corresponden, punto por punto, con los conceptos incluido en el modelo:

A) Fueron producidos -en horario de máxima audiencia y en formato similar- por una cadena nacional pública y por uno de los grupos audiovisuales privados más relevantes del país: el 22 de abril en Televisión Española (TVE) y el día siguiente, el 23, en Atresmedia (Antena 3 Televisión y La Sexta). Para el Subdirector de Informativos de Antena 3 Televisión, Óscar Vázquez, "la emisión de los debates electorales y los programas previos y posteriores nos ha reforzado como grupo de comunicación en el papel de servicio público. Convertirse en referencia informativa en cuestiones tan relevantes refuerza nuestra imagen y la credibilidad de nuestros productos. Apostar por la 
información es una declaración de intenciones que cobra sentido cuando planteamos emitir programas de este corte en el prime time de nuestra programación"1.

B) En los dos debates analizados se puede constatar que han servido, en primer lugar, 1) para construir un auténtico acontecimiento mediático, tanto en el contexto del sistema político (lógica política) como en el de los propios medios de comunicación (lógica mediática). Como todo acontecimiento, los debates han tenido sus prolegómenos -mediáticos y no mediáticos- que han servido para crear expectativas y para investir semánticamente el acto central de los debates -en este caso, dos encadenados en muy poco tiempo-. Y, en segundo lugar, 2) como una ceremonia de confrontación entre los candidatos.

En nuestro caso, en el último debate, el acontecimiento mediático se ha construido a partir de la celebración de dos debates sucesivos -los ya comentados- que han permitido que los candidatos establecieran -como en un juego eliminatorio en dos partidos- una estrategia definida en función de sus propios intereses. Por su parte, los periodistas y los medios han contribuido con sus informaciones, en paralelo y precedentes y consecuentes, a focalizar la atención pública en torno al acontecimiento, crear suspense, presentarse ante los ciudadanos como los árbitros neutrales de la confrontación y convocar una gran cantidad de audiencia, tanto en los debates como en el resto de los ámbitos que constituían el evento mediático.

C) El carácter de acontecimiento mediático de los debates se aseguró, por otra parte, mediante diversos flujos de informaciones, polémicas y actos de promoción que le precedieron y le sucedieron. Además, la promoción del debate incluyó siempre valores relacionados con su importancia, su trascendencia política y su carácter decisivo -el segundo debate fue promocionado precisamente como "debate decisivo"- que hacía de su visionado algo cuasi obligatorio.

Los datos de audiencia de los dos debates, los que reconocemos como ámbito mediático central, consiguieron índices de audiencia memorables. El primer debate alcanzó un share de $43.8 \%$ de cuota de pantalla y una audiencia de 8.886.000 telespectadores. El segundo, por su parte, obtuvo una cuota mayor, $48,8 \%$ y casi 9 millones y medio de televidentes.

Por otra parte, el volumen de audiencia conseguido por los debates, así como su repercusión mediática transversal consiguió generar un ámbito mediático periférico de considerable envergadura. Fueron muchos los medios sociales que participaron, los periódicos que previa y posteriormente se hicieron eco, los subproductos audiovisuales del debate que se extendieron por las redes sociales, e innumerables los foros de discusión sobre el sentido final del debate y su resolución.

Con todo ello, queda identificada la vertiente de acontecimiento mediático que asume el debate.

\subsection{Regulación conflictiva}

Por otro lado, también se puede identificar con facilidad la dimensión de regulación que ha de estar presente en todo acontecimiento mediático ceremonial. Su regulación ha sido el resultado de un constante conflicto-negociación y consenso entre las partes: A) Tras innumerables tira y afloja de muchas de las partes implicadas, se produjo un acontecimiento novedoso: por primera vez en la historia democrática de España se darían dos debates en dos días consecutivos, uno en la TV pública y otro en dos televisiones privadas del mismo grupo de comunicación. Todo ello rodeado de mucha incertidumbre que acentuaba el suspense mediático: solo tres horas antes del debate, la Junta

${ }^{1}$ En una entrevista realizada en Antena 3 Televisión, en Madrid, el 1 de julio de 2019. 
electoral rechazó el recurso del Partido Popular contra el ordenamiento de los turnos de los 4 candidatos y que acaba reforzando el papel de la lógica mediática por encima de la política -según la entienden uno de los partidos-: "Desestimar la reclamación por cuanto la organización del debate entra dentro del ámbito de autonomía del medio y, sobre todo, porque en el presente caso la forma en que ha sido ejercida no resulta arbitraria ni de forma global contraria al principio de proporcionalidad" (Junta Electoral). B) En el caso de los debates analizados, se comprueba que las normas de funcionamiento -pero también su posibilidad y sus horarios- dieron lugar a un enfrentamiento entre diversas instancias de regulación, algunas de ellas judiciales, otras políticas y otras mediáticas. Todo ello sirvió para hacer de los debates un acontecimiento especial, decisivo en la lógica política -puesto que ayudaba, en teoría, para decidir el voto-, pero también decisivo en la lógica mediática porque más allá de su importancia, cumplía una función dramática: despertaba expectativas creaba tensión y suspense y se presentaba como una prueba decisiva.

\subsection{Marco general del acontecimiento}

Desde el punto de vista del marco funcional o pragmático, podemos identificar en el debate analizado su carácter de confrontación. Es evidente, desde muchos puntos de vista, que el acontecimiento mediático de los debates se presenta como un reto mediático de confrontación (Dayan y Katz, 1995) que da lugar a la proclamación -consagración- del ganador y en su celebración como una especie de héroe.

En términos del enfoque antropológico de la comunicación, y más concretamente, desde el punto de vista de la teoría de la televisión ceremonial (Dayan y Katz, 1994), el acontecimiento se puede resumir como un episodio de confrontación.

Es indudable que reúne todos los requisitos que este tipo de acontecimientos exige: a) Periodicidad cíclica: se inscriben en la tradición de los debates electorales en España; b) Reglas negociadas: todos los participantes e, incluso, instancias jurídicas y mediáticas; c) Igualdad de partida: asegurada, entre otras cosas por la igualdad de tiempos de que disfrutan todos los candidatos; d) Tensión dramática: ¿quién será el candidato ganador?; e) Papel de actor: los candidatos tienen que respetar las reglas acordadas e, incluso, cuentan con una segunda oportunidad (el segundo debate); f) Papel neutral de los moderadores: los periodistas se presentan como independientes y no interviene ni a favor ni en contra de ninguno de los candidatos; g) Papel del público: espectadores y sancionadores finales de la realización de la prueba; h) Mensaje central: hay que respetar las reglas, fue una apelación constante dentro y fuera de los programas; i) Racionalidad invocada: en todos los debates se apelaba a la racionalidad y la lógica de la democracia; j) Relación de conflicto: se desarrolla en el conjunto de reglas aceptado y, a través, de las intervenciones de los candidatos; k) Orientación temporal: presente, con el referente inmediato de las próximas elecciones.

Además, desde el punto de vista semionarrativo, los dos debates analizados se configuran como una prueba competitiva calificante entre los candidatos. Esto se aprecia en el hecho de que muchas informaciones y comentarios crean suspense sobre el desenlace y que muchos estudios buscan poner de manifiesto quién acabará siendo proclamado ganador.

Desde el punto de vista de la dimensión semántica, tanto los personajes como la situación de confrontación -la prueba- son presentados, mediante diversas estrategias de investidura sémica, como un juego teatral -representación y competición al mismo tiempo-. La teatralidad viene marcada por la recepción, a pie de calle, a todos los candidatos, por su paso por los camerinos para ser maquillados -rasgos todos ellos que son isomórficos con la función de los actores de teatro-. Por otra parte, la competición-prueba se inviste de connotaciones propias de las competiciones deportivas. 
Los candidatos se presentan como deportistas que: a) disponen de asesores-entrenadores y masajistas-asistentes, que se cuidan de ellos en los descansos; b) Realizan fases de calentamiento y descansos para reparación y avituallamiento; d) son regulados y arbitrados -al menos en lo que en el uso del tiempo se refiere- por un equipo de árbitros de baloncesto; mientras los periodistas se asemejan a los jueces de mesa de un equipo de baloncesto. En fin, todo ello asegura que el marco de interpretación de la televisión a los espectadores sea el de una representación teatralizada de una especie de juego deportivo-político.

\subsection{La secuencia narrativa de la prueba}

Como un rasgo más identificado en nuestro marco conceptual, en estos debates es manifiestamente visible que se trata de una prueba de confrontación calificante que los candidatos han de superar. En ella influye tanto la posición actancial de los candidatos como el desenlace del proceso.

Todos los candidatos parten de una posición actancial de igualdad, o sea, son sujetos de la acción que buscan la consecución del objeto de deseo -la victoria electoral- para lo cual tiene que superar en la prueba del debate al resto de candidatos que son también héroes que aspiran al mismo objeto de deseo.

Un análisis de las posiciones de los diversos candidatos muestra que Rivera distribuye ataques por igual a casi todos los candidatos; que Casado tiende a defenderse de Rivera, y le ataca tímidamente, mientras concentra sus ataques en Sánchez y secundariamente en Iglesias. Que Sánchez ataca por igual a Casado y a Rivera, mientras que no ataca, casi nunca, a Iglesias. Lo mismo hace éste, que concentra sus ataques en Casado y Rivera. La tendencia de Sánchez es unificar a Casado y Rivera en el mismo actante, mientras que Iglesias hace lo mismo.

Todos los candidatos se muestran casi siempre en la posición de actantes-sujetos. El único que cambia, de cuando en cuando, de posición, tratándose de convertirse en actante-destinatario es Iglesias. Con ello lo que busca es establecer reglas de conversación que quiere imponer a sus compañeros y situarse en posición de sancionador de aquellos con quienes en principio son contendientes en igualdad. Para ello, a veces, se vale ostentosamente de la utilización -oral y visualde la Constitución como regla fundamental. Así se inviste él mismo de la autoridad que le confiere la constitución. Mientras tanto, los demás candidatos, no osan más que convocar a otros actantes ayudantes -fotografías, gráficos, etc.-. Y, curiosamente, ninguno de ellos planta cara al cambio actancial que trata de operar Iglesias.

\subsection{Las acciones de los protagonistas}

En el marco de la confrontación ritual ya señalada, cabe, no obstante, asumir algunos enfoques y conceptos propios de un análisis más funcional, como es el propuesto por Benoit (1995). Las acciones que estos héroes-candidatos pueden realizar son definidas por citado autor: aclamación, ataque y defensa.

Efectivamente, todos los actores se mueven en estas posiciones. A) Aclamaciones (Schlenker, 1980), frases que tienden a beneficiar la reputación del candidato (Benoit, 1995). B) Ataques (Pfau y Kenski, 1990; Jamieson, 1992). C) Defensas (Brinson y Benoit, 1996) en las que un candidato trata de reparar el daño infringido por un ataque de otro candidato o de un periodista. Por nuestra parte, hemos distinguido en el análisis entre: a) las aclamaciones, ataques y defensas dirigidas a los programas, acciones o políticas de los candidatos, y b) las dirigidas a los candidatos en sí como actores dotados de ciertas cualidades y atributos; y, dentro de estas, unas orientadas a valorar 1) la 
dimensión enunciativa de cada candidato -veracidad-; y 2) sus atributos específicos como sujeto, su ser. Estas distinciones nos permiten establecer una graduación del nivel de agresividad de las intervenciones de los candidatos, lo que, a fin de cuentas, acaba midiendo el nivel de confianza (cooperación)-desconfianza (conflicto) entre unos candidatos y otros. Así, cuantos más ataques -y defensas- se dirijan hacia el ser del sujeto o hacia su dimensión enunciativa, más agresividad discursiva y mayor desconfianza (conflictividad). Por contra, cuanto más ataques -y defensas- se dirijan al programa, menos desconfianza y mayor grado de negociación.

En los debates analizados, las intervenciones más agresivas van desde Sánchez-Iglesias hacia Casado-Rivera. Especialmente Sánchez acentúa sus ataques desde la veracidad enunciativa de sus oponentes -verdad/mentira- hasta los atributos como sujetos -mentirosos-. Los ataques-defensas entre Sánchez e Iglesias apenas existen y se limitan al nivel de confrontación entre políticas. Casado es poco agresivo con Rivera, mientras este último lo es con todos.

\subsection{Las estrategias enunciativas}

El conjunto de acciones discursivas y de búsqueda de posicionamientos actanciales -así como la estructura semántica de los candidatos- acaba definiendo su propia estrategia discursiva. Sánchez procura presentarse como un héroe cooperativo con la izquierda, y agresivo con los candidatos de la derecha. Iglesias busca cercanía con Sánchez y, al mismo tiempo, superioridad con respecto a él -y al resto de candidatos- autopresentándose como el destinador que establece las reglas de juego y distribuye los deberes al resto. Casado trata de jugar un papel simétrico y contrario al de Sánchez, mientras que Rivera juega contra todos, autoproclamándose el único merecedor del objeto de deseo. La agresividad marca el estilo de todos, menos el de Iglesias, que se presenta como el más moderado y moderador. Todos parten como iguales, pero Iglesias busca presentarse como el más maduro y responsable.

En todas ellas se advierten rasgos específicos de la mediatización: personalización; aceptación de la audiencia como destinador final; asunción por parte de los candidatos de todas las reglas mediáticas establecidas; reformateo de los mensajes en términos mediáticos; etc.

\section{Resultados y conclusiones}

Del análisis, aún provisional -en cuanto a resultados-, y a la espera de seguir avanzando en otros casos concretos, cabe deducir que el modelo propuesto resulta perfectamente funcional y demuestra coherencia y capacidad para reunir en su seno aportaciones provenientes de diferentes marcos conceptuales.

De hecho, se advierte una compatibilidad manifiesta entre todos los conceptos utilizados, una vez que han sido aplicados a un estudio concreto. Este modelo nos ha permitido: a) Una visión holística y sistémica del acontecimiento mediático; b) La distinción entre diversos niveles de análisis; y c) La identificación de la función de regulación y de estructuración de los flujos informacionales.

La aplicación del modelo propuesto permite, pues, identificar tanto los efectos de la mediatización política como la marcada tendencia a crear gestalt -marcos perceptivos- ceremoniales ante acontecimientos mediáticos planificados.

Permite, consecuentemente, estudiar de forma integrada las dimensiones pragmáticas, narrativas y enunciativas. Y permite también reconocer las estrategias basadas en la asunción de diferentes 
posiciones actanciales -por parte de algún candidato- y el valor de la gradación de la agresividad y la conflictividad.

Al mismo tiempo, hemos visto que, como efecto de la mediatización intensiva que se ha producido en las últimas décadas, se han podido poner de relieve: a) la construcción calculada, en términos de lógica mediática, del acontecimiento; y b) el isomorfismo entre la competición deportiva -uno de los géneros más destacados de la lógica mediática actual- y la confrontación política -propia del sistema institucional político reglado democráticamente-.

Finalmente, hemos visto que el modelo propuesto reúne el suficiente poder explicativo y la necesaria flexibilidad como para permitirnos analizar con provecho su capacidad para estudiar y describir suficientemente las estrategias discursivas; en concreto, lo que hemos llamado: la prueba calificante.

De cara a futuras investigaciones, será útil, en todo caso: a) Ampliar el corpus de análisis, haciéndolo más diverso y contrastado, con objeto de comprobar la validez de algunas de las nociones generales; b) Focalizar el análisis en algunos de los aspectos más significativos del modelo -carácter ceremonial, estrategias discursivas, caracterización de la prueba, etc.- con objeto de poder ofrecer resultados más empíricos y desarrollar la aplicabilidad y practicidad del modelo. c) Enmarcar el análisis de las estrategias discursivas -o algunos de sus aspectos- en el análisis general del discurso político y de la mediatización como fenómeno social general. Esto nos permitiría reforzar los aspectos conceptuales y teóricos.

\section{Referencias}

Adam, S. \& Maier, M. (2010). Personalization of politics. A critical review and agenda for research. Annals of the International Communication Association, 34(1), 213-257.

Allern, S. \& Blach Orsten, M. (2011). The news media as a political institution. A Scandinavian perspective. Journalism Studies, 12(1), 92-105.

Altheide D. L. \& Snow R.P. (1979). Media Logic. Sage.

Austin, J. (2016). Cómo hacer cosas con palabras. Palabras y acciones. Paidós.

Balmas, M. \& Sheafer, T. (2013). Leaders first, countries after: Mediated political personalization in the international arena. Journal of communication, 63(3), 454-475.

Beck, U. (1996). The Reinvention of Politics. Rethinking Modernity in the Global Social Order. Polity Press.

Bennet, W. L. (1995). News: The Politics of Illusion. Longman.

Bennett, W. L. \& Entman, R. M. (2001). Mediated Politics. Communication in the Future or Democracy. Cambridge University Press.

Benoit, W. L. (1995). Accounts, excuses, and apologies: A theory of image restoration. State University of New York Press.

Berardi, F. (2017). Futurability. The Age of Impotence and the Horizon of Possibility. Verso. 
Blumler, J. G. \& Gurevitch, M. (1995). The Crisis of Public Communication. Routledge.

Brinson, S. L. \& Benoit, W.L. (1996). Dow Corning's image repair strategies in the breast implant crisis. Communication Quarterly, 44(1), 29-41.

Bucy, E. \& Gregson, S. (2001). Media Participation: A Legitimizing Mechanism of Mass Democracy. News Media and Society, 3(3), 357-380.

Galindo, F. (1998). El debate político actual. Andavira Editora.

Canel, M. J. \& Sanders, K. (2012). Government communication: an emerging field in Political Communication research. En Semetko, H. \& Scammell. M. (Eds). The Sage Handbook of Political Communication. Sage, 85-96.

Casero-Ripollés, A. (2008). Modelos de relación entre periodistas y políticos: La perspectiva de la negociación constante. Estudios sobre el mensaje periodístico, (14), 111-128.

Casero-Ripollés, A. (2009). La construcción mediática de las crisis políticas. Fragua.

Castells, M. (2009). Communication power. Oxford University Press.

Chadwick, A. (2013). The hybrid media system: Politics and power. Oxford University Press.

Cook, T. (1998). Governing with the news: The news media as political institutions. University of Chicago Press.

Couldry, N. (2003). Media Rituals. Routledge.

Couldry, N. (2008). Mediatization or Mediation? Alternative understandings of the emergent space of digital storytelling. New Media and Society, 10(3), 373-391.

Couldry, N. (2012). Media Society, World, Social Theory and Digital Media Practice. Polity Press.

Couldry N. \& Hepp, A. (2013). Conceptualizing Mediatizations: Contexts, Traditions, Arguments. Communication Theory, 23(3), 191-202.

Dahlgren, P. (2005). The Internet, Public Spheres, and Political Communication. Dispersion and Deliberation. Journal of Political Communication, 22(2), 147-162.

Dayan, D. \& Katz, E. (1994). Media Events. Harvard University Press.

Dahl, R. (1991). La Democracia y sus Críticos. Paidós.

Enli, G. \& Skogerbo, E. (2013). Personalized campaigns in party-centred politics: Twitter and Facebook as arenas for political communication. Information, communication \& society, 16(5), 757-774.

Goffman, E. (1974). Frame Analysis: An Essay on the Organization of Experience. Northeastern University Press. 
Greimas, A., Courtés, J. et al. (1982). Semiotics and Language: An Analytical Dictionary. Bloomington: Indiana University Press.

Gil de Zúñiga, H.; Jung, N. \& Valenzuela, S. (2012). Social media use for news and individuals' social capital, civic engagement and political participation. Journal of computer-mediated communication, 17(3), 319-336.

Habermas, J. (1983). Historia ya crítica de la opinión pública. Gustavo Gili.

Heinich, N. (2012). De la visibilité. Excellence et singularité en régime médiatique. Gallimard.

Herrero J. C. y Benoit, W. L. (2009). Análisis funcional de los debates en las elecciones generales de 2008. ZER, 14(27), 61-81.

Hjarvard, S. (2013). The Mediatization of Culture and Society. Routledge.

Hepp, A. (2011). Cultures of Mediatization. Polity Press.

Jamieson, K. H. (1992). Dirty Politics: Deception, Distraction, and Democracy. Oxford University Press.

Katz, E. (1980). Media Events: The Sense of Occasion. Studies in Visual Communication, 6(3), 8489. http://repository.upenn.edu/asc_papers/263

Krämer, B. (2014). Media Populism: A Conceptual Clarification and Some Theses on its Effects. Communication Theory, 24(1), 42-60.

Livingstone, S. (2009). On the mediation of everything: ICA presidential address 2008. Journal of Communication, 59(1), 1-18.

Lakoff, G. (2017). No pienses en un elefante. Lenguaje y debate politico. Editorial Complutense.

Livingstone, S. y Lunt, P. (2014). Mediatization: an emerging paradigm for media and communication studies. En Lundby, K. (Ed.). Mediatization of Communication. Handbook of Communication Science, 21. De Gruyter Mouton.

Meyen, M.; Thieroff, M. \& Strenger, S. (2014). Mass media logic and the mediatization of politics: a theoretical framework. Journalism studies, 15(3), 271- 288.

Pfau, M. \& Kenski, H. C. (1990). Attack politics: Strategy and defense. Praeger.

Postill, J. (2018). Populism and social media: a global perspective. Media, Culture \& Society, 40(5), 754-765.

Proaño, L. E. (2002). Sugerencias para el diseño de una campaña electoral. Chasqui, Revista Latinoamericana de Comunicación, (77).

Quintas, E. y Quintas, N. (2010). Cara a cara electoral televisado. Análisis audiovisual de los debates entre los candidatos a la presidencia española (2008). Miguel Hernández Communication Journal, (1), 20-39. 
RLCS, Revista Latina de Comunicación Social, 76, 229-245

[Investigación] DOI: 10.4185/RLCS-2020-1445 | ISSN 1138-5820 | Año 2020

Schlenker, B. R. (1980). Impression Management: The Self-Concept, Social Identity, and Interpersonal Relations. CA: Brooks/Cole.

Searle, J. (1969). Speech Acts: An Essay in the Philosophy of Language. Cambridge University Press.

Soengas, X. (2009). The limits of information in the negotiated debates. Revista Latina de Comunicación Social, (64), 988-999. Universidad de La Laguna.

Sparrow, B. H. (1999). Uncertain Guardians: The news media as institutions. The Johns Hopkins University.

Strömbäck J. \& Esser F. (2014). Mediatization of Politics: Towards a Theoretical Framework. En Esser F. \& Strömbäck J. (Eds). Mediatization of Politics. Palgrave Macmillan.

Strömbäck J. (2008). Four Phases of Mediatization: An Analysis of the Mediatization of Politics. The International Journal of Press/Politics, 13(3), 228-246.

Sunstein, C. R. (2002). The Law of Group Polarization. The Journal of Political Philosophy, (10), 2.

Tavoillot, P. H. (2019). Comment gouverner un peuple roi? Traité nouveau d'art politique. Odile Jacob.

Thompson, M. (2016). Enough Said: What's Gone Wrong with the Language of Politics? St. Martin's Press.

\section{AUTORES:}

\section{Carles Marín Lladó}

Profesor titular de Periodismo Audiovisual en la Universidad Rey Juan Carlos (URJC) desde 2003. Se ha especializado en la información televisiva y radiofónica a partir de su análisis discursivo. Desde 2012 dirige el Máster en Reporterismo de Televisión en la misma universidad. Ha publicado una decena de libros y numerosos artículos sobre reporterismo e informativos audiovisuales, y cuenta con una larga trayectoria en TV y radio como creador de formatos, director, guionista y reportero tanto de programas informativos como de infoentretenimiento. Ha sido vicerrector y vicedecano de la URJC y directivo de la Academia de las Ciencias y las Artes de Televisión (AcademiaTV).

carles.marin@urjc.es

Índice H: 5

Orcid ID: https://orcid.org/0000-0001-7456-5889

Google Scholar: https://scholar.google.es/citations?user=3xduXAgAAAAJ\&hl=es

\section{José Manuel Pérez Tornero}

Catedrático de Periodismo en la Universidad Autónoma de Barcelona. Director de la Cátedra UNESCO Media and Information Literacy and Quality Journalism. Dirige los másteres de Gestión de la Comunicación Política y Electoral y Comunicación y Educación de la UAB. Es el director del Research Group Communication and Education (UAB). Forma parte del Grupo de Expertos de la UE sobre Media Literacy, y de GAPMIL (UNESCO). Especializado en Televisión, cultural y Educativa. Ha sido director de Televisión Educativa en RTVE y es miembro del Consejo Directivo de la Asociación de Televisiones Educativas Iberoamericanas (ATEI). 
RLCS, Revista Latina de Comunicación Social, 76, 229-245

[Investigación] DOI: 10.4185/RLCS-2020-1445 | ISSN 1138-5820 | Año 2020

josepmanuel.perez@uab.es

Índice H: 33

Orcid ID: https://orcid.org/0000-0002-8198-3648

Google Scholar: https://scholar.google.es/citations?user=03vc9SwAAAAJ\&hl=es 